DUTRA E SILVA, Sandro; SÁ, Dominichi Miranda; SÁ, Magali R. (Orgs.). Vastos Sertões: História e Natureza na Ciência e na Literatura. Rio de Janeiro, RJ: Mauad X, 2015. v. 1.

\title{
Visões do Sertão
}

\section{Visions of Brazilians Wilderness}

"Vastos Sertões: história e natureza na ciência e na literatura", uma obra organizada por Sandro Dutra e Silva, Dominichi Miranda de Sá e Magali Romero Sá, busca reunir diferentes interpretações e variedades de olhares sobre o sertão, com o objetivo de discutir a associação entre a construção do país e a conquista da natureza. Assim, a mesma é dividida em três partes que compreendem uma coletânea de artigos, explorando os vastos sertões do Brasil e utilizando-se da interdisciplinaridade, por meio de um diálogo que envolve especialistas da área da História Ambiental, História das Ciências, História Política, Intelectual, dentre outros.

A primeira parte da obra é denominada "História e natureza na interpretação da ocupação dos sertões e do Oeste", a segunda parte, trata da "História e natureza na ciência", e por fim a terceira parte da obra é intitulada "História, natureza e literatura".

O sertão, considerado sinônimo da ausência de leis, da violência e do atraso já foi objeto de muitas interpretações, como as dos autores Capistrano de Abreu, Gilberto Freyre, Sérgio Buarque de Holanda e Caio Prado Junior. Nesse sentido, percebe-se o grande valor da obra, revisitando uma temática clássica com a intenção de somar e ressaltar a importância do sertão na história da imaginação sobre a natureza e nos projetos de construção do país, como um viés para a leitura do Brasil.

Assim sendo, a primeira parte busca evidenciar o diálogo com a História Ambiental e os processos históricos nas diferentes interseções, entre as experiências brasileiras e norte-americanas entre a fronteira e o sertão. O primeiro artigo é denominado "A natureza na interpretação do Oeste: sertão e fronteira no pensamento brasileiro" de Lucia Lippi Oliveira, no qual a autora analisa por meio do pensamento social e geográfico os

\footnotetext{
${ }^{1}$ Mestranda do Programa de Pós Graduação em História pela Unicentro - PR
} 
diferentes significados da palavra sertão, discutindo e relacionando diversos autores e também com a produção nacional e norte-americana de frontier. A autora afirma que, assim como as diferentes interpretações da natureza brasileira, vista por Pero Vaz Caminha como paradisíaca e pelos jesuítas como terrível e estranha, o mesmo ocorre com as visões referentes ao sertão, as quais podem ser classificadas, inicialmente, por meio de duas vertentes. A primeira delas é a visão romântica, nesse pensamento o sertanejo aparece como símbolo nacional pelo seu modo de vida caracterizado pela simplicidade e destreza. A segunda perspectiva é chamada pela autora de realista, a qual trata o sertanejo como um problema pelo fato de se opor à urbanização. Dentro dessa perspectiva a também autora discute o papel das bandeiras e dos bandeirantes como construtores da nacionalidade.

O segundo capítulo da coletânea, de Arthur Lima de Ávila, "Da História da Fronteira à História do Oeste: fragmentação da crise na West History norte-americana no século XX" propõe-se a explorar a transformação da historiografia da fronteira dos EUA, que passa de uma história da nação para a história de uma região, especificamente, o Oeste. Nesse capítulo, Ávila traz diversos autores como aportes teóricos para analisar a transformação da West History em um campo dedicado apenas à História do Oeste e da Fronteira e não mais compreendida como história nacional, como era inicialmente. Nessa visão, institucionalizada na década de 1890, fronteira é vista como uma zona de intervenção cultural entre dois grupos e identidade como a mestiçagem cultural. Assim, no decorrer do texto, Ávila vai analisar os processos que foram importantes para a mudança nos panoramas de estudar e fazer história.

O terceiro capítulo foi escrito por Sandro Dutra e Silva, Giovana Galvão Tavares, Dominichi Miranda de Sá e José Luiz de Andrade Franco, denominado "A construção simbólica do Oeste brasileiro (19301940)", busca compreender por meio da História Ambiental o Oeste brasileiro, assim, os autores dialogam com os conceitos de frontier e wildeness relacionando com as políticas de ocupação territorial, com ênfase para os discursos da "Marcha para o Oeste", que era uma região tida como terra livre e rica em recursos naturais. São principais referências nesse capítulo os autores Donald Woster e Henry Nash Smith. Utilizando-se desses conceitos e autores, o texto expressa com clareza as tentativas de construir simbolicamente o Oeste por meio das políticas de ocupação territorial promovidas durante no período do Estado Novo do governo de Getúlio Vargas, com ênfase especial nos discursos da "Marcha para o Oeste". 
O capítulo que segue é intitulado "A natureza dos conflitos da atividade de mineração de ouro nos sertões das Minas Gerais" de Carolina Marotta Capanema. Trata-se de uma análise da busca pelo Eldorado na América portuguesa, dentro dessa atividade a autora analisa os usos da madeira nos núcleos urbanos e as relações de conflitos ligadas a essa utilização, além da regulação e dos conflitos no que diz respeito à utilização das águas. Nesse sentido, já na parte final do texto a autora trabalha a relação natureza e sustentação de estruturas de poder, analisando a questão das minas e dos serviços de mineração e sua submissão às regulamentações e contingências da época.

O capítulo seguinte de Claiton Marcio da Silva, tem como título "Os outros são o atraso: populações rurais e modernização agrícola em Minas Gerais (1950-1960)" e analisa os processos de resistência do sertão à modernização que é vista aqui sob a perspectiva da expansão de programas de extensão rural no Brasil. Esses programas de extensão rural buscavam a introdução da chamada moderna agricultura e foi por meio destes programas que técnicos agrícolas e agrônomos entraram em contato com as populações da zona rural mineira, os quais apresentaram resistências à modernização. Esse contato foi importante e mostrou uma imagem do atraso no Brasil e de suas técnicas primitivas. Tais resistências geraram dificuldades na aceitação da modernização que seguia o modelo americano das farmers, com tecnologias como o milho híbrido, fertilizantes e pesticidas.

A segunda parte do livro, "História e natureza na ciência" é composta por seis artigos e busca criar uma ponte entre História Ambiental e História das Ciências, tendo como proposta geral analisar o conhecimento produzido por viajantes naturalistas, biólogos, geógrafos, cientistas e agrônomos.

O primeiro capítulo, de Fabíula Sevilha de Souza "Na imensidão do Cerrado a [in]domável natureza: sertão, fronteira e viajantes em Goiás na primeira metade do século XIX" analisa os relatos dos viajantes e a visão que estes tinham do sertão goiano como uma região doente e do indígena como obstáculo à civilização. Além disso, a autora destaca os esforços destes viajantes em buscar utilidade de Goiás para o país em construção e em suas palavras "domar o indomável".

O capítulo que segue "Entre o mar e o sertão: a expedição biológica do belga Jean Massart ao Brasil em 1922-1923" é escrito por Alda Heizer. A autora analisa a passagem do médico cientista Massart pela Estação Biológica de Itatiaia no Rio de Janeiro, a qual viria a ser a primeira unidade de conservação no Brasil. A autora analisa também a visão de Jean 
Massart em relação à proteção da natureza. Além de apresentar os registros fotográficos, Heizer destaca a imagem presente nos escritos de Massart sobre o sertão a visão de uma terra distante do litoral e à ausência do poder pública.

"Capistrano de Abreu e Friedrich Ratzel na história da ocupação dos sertões brasileiros", escrito por Ricardo Alexandre Santos de Sousa, trata do encontro entre o homem e a natureza no papel da formação da nacionalidade. Em sua análise, Sousa evidencia Capistrano e as ideias de seu tempo. O autor afirma que de acordo com Friedrich Ratzel, Capistrano desqualificou as bandeiras paulistas em detrimento da valorização das trocas culturais com os povos indígenas, com relação a delineação da nacionalidade brasileira, dando assim, voz a personagens que lhe pareciam desconsiderados quando submetidos ao olhar civilizador europeu.

Em "A nova capital do Brasil: ciência e política nas comissões de estudos do Planalto Central das décadas de 1940 e 1950" de Tamara Rangel e Nísia Trindade Lima exploram os projetos de construção de Brasília, localizada no sertão por meio dos estudos e argumentos geopolíticos e médicos para a escolha da localização da nova capital do país em consonância com as ideias da Marcha para o Oeste, centrando a análise sobre as comissões organizadas pelo governo federal.

Tema semelhante também é abordado no capítulo seguinte "A ecologia do Planalto Central do Brasil: as pesquisas de Henrique Pimenta Veloso nos anos 1940" de autoria de Dominichi Miranda de Sá e Magali Romero de Sá. Nesse trabalho, as autoras buscam compreender os estudos feitos pelo engenheiro agrônomo Henrique Pimenta Veloso por meio do Instituto Oswaldo Cruz (IOC). Esses estudos ecológicos trataram da vegetação no Centro-Oeste do Brasil, região esta que teve atenção especial nos estudos do IOC. Para a realização desses estudos, Veloso realizou duas viagens para a região, sendo a primeira em 1946 com o intuito de analisar as associações de zona de transição entre o Cerrado e as matas pluviais amazônicas, e a segunda em 1947 para analisar as condições fitoecológicas da região do Cerrado.

"A civilização da mandioca sob os cuidados da Nutrição: escritos sobre a alimentação da Amazônia", escrito por Rômulo de Paula Andrade e Gilberto Hochman busca analisar os debates relacionadas à questões de saúde, higiene, fome e desnutrição dos caboclos da Amazônia e sua relação com o suposto atraso das práticas extrativistas. Os autores destacam o papel dos nutrólogos Josué de Castro e Dante Costa ao explorar temas como a escassez alimentar, a preocupação com a monocultura da 
mandioca e o isolamento espacial vivido por homens e mulheres da Amazônia.

A terceira parte da obra "História, natureza e literatura", é composta por cinco artigos que buscam por meio de crônicas históricas evidenciar a importância dos conceitos de fronteira e sertão na cultura brasileira.

O primeiro capítulo da terceira parte da coletânea é escrito por Victória Saramago e é denominado "O sertão ao redor do mundo: escritos portugueses do século XVI" a autora examina os usos do termo "sertão" nas crônicas portuguesas e seus níveis de certeza, especulações ou a busca de signos pelos autores destes escritos sobre o sertão.

"A vida sertaneja entre a ficção e o testemunho: os 'Quadros e Costumes do Nordeste' de Graciliano Ramos" de Thiago Mio Salla desenvolve uma argumentação sobre a colaboração de Graciliano Ramos para a revista Cultura Política e suas crônicas mensais na seção 'Quadros e Costumes do Nordeste', que por mais que dirigisse diversas críticas aos problemas estruturais do período também servia como uma estratégia para publicar suas ideias na revista. Salla aponta diversas ambiguidades na escrita de Graciliano Ramos analisando suas linhas de fugas e apropriações.

$\mathrm{O}$ artigo seguinte "'O ambiente perdido do distante sertão': homem e natureza na prosa de Bernardo Élis" escrito por Luciana Murari, tem por objetivo principal apresentar a diversas formas de intercâmbio entre homem e natureza, apresentada na descrição das paisagens, na dramaticidade de seus enredos evidenciando a sensibilidade literária do autor. Tratando do mesmo autor, o artigo "Ermos sertões, distantes gerais: o Cerrado na literatura de Bernardo Élis" de Sandro Dutra e Silva, Aurea Marchetti Bandeira e Tálliton Túlio de Moura busca estabelecer uma relação entre a sociedade e natureza nas paisagens do Cerrado e Fronteira e Natureza.

O último artigo da coletânea trata também dos escritos de Bernardo Élis, em especial a obra "O tronco" comparando-a com a de outros autores clássicos, como Graciliano Ramos, Afonso Arinos, José Lins do Rego, dentre outros, busca investigar a presença dos jagunços na literatura de Élis e é intitulado "Colonialismo no grande sertão: os jagunços de Bernardo Élis" da autora Wilma Martins de Mendonça Thiago Fernandes Soares Ribeiro.

Trata-se de uma obra que faz um diálogo interdisciplinar entre História Ambiental e História das Ciências, reunindo diversas interpretações sobre o sertão, discutindo a ligação entre a conquista da natureza e a 
construção do país por meio do dialogo com as mais variadas fontes, conforme já destacado.

Concluindo, pode-se dizer que a obra é de certa forma, um pontapé inicial para outros trabalhos de historiadores e pesquisadores que possam vir a contribuir não apenas para a História Regional, mas para a História Ambiental, o que nos leva a contemplar a magnitude de se estudar e fazer História. 